\title{
O Ensino de Matemática e pesquisa-ação no primeiro ciclo dos Anos Iniciais
}

\section{The Teaching of Mathematics and Action Research in the first cycle of the Early Years}

\author{
Rúbia Emmel (rubia.emmel@iffarroupilha.edu.br) \\ Instituto Federal Farroupilha, Câmpus Santa Rosa
}

Andrieli Tais Hahn Rodrigues (andrielihahn@ colegiodomhermeto.com.br); Setrem, Faculdades Três de Maio

Amanda Denes (amandadenes2013@gmail.com); Setrem, Faculdades Três de Maio

\begin{abstract}
Resumo:
Este relato teve o objetivo geral de compreender o ensino de Matemática nos anos iniciais em uma Escola Municipal de Ensino Fundamental. Utilizou-se como metodologia a pesquisa-ação que permitiu investigar as metodologias de ensino utilizadas pelos professores, possibilitando-se a participação dos alunos de uma turma do segundo ano. Por meio da pesquisa-ação refletiu-se no interstício da prática docente, pois foram realizadas etapas de observação, planejamento e intervenção do ensino de Matemática. A análise dos resultados evidenciou que nos anos iniciais se requer a utilização do lúdico, ambientes diferenciados e equipados com materiais concretos, qualificando os processos de ensino e de aprendizagem em Educação Matemática. Portanto, este relato possibilitou como professoras pesquisadoras de nossas próprias práticas em movimento de pesquisa-ação ampliar nossas compreensões sobre o ensino da Matemática nos anos iniciais do Ensino Fundamental de modo a contribuir para a aprendizagem dos alunos.
\end{abstract}

Palavras-chave: Educação Matemática; Anos Iniciais; Pesquisa-ação.

\begin{abstract}
:
This report in Mathematics education had the general objective to understand the teaching of mathematics in the initial years in a Municipal School of Elementary Education. It was used as methodology the action research that allowed to investigate the teaching methodologies used by the teachers, allowing the participation of the students of a class of the second year. Through the action research was reflected in the interstice of the teaching practice, since steps of observation, planning and intervention of the teaching of Mathematics. The analysis of the results showed that in the initial years it is required the use of playful, differentiated environments and equipped with concrete materials, qualifying the processes of teaching and learning in Mathematics Education. Therefore, this report made it possible as research teachers of our own practices in the action-research movement to broaden our understanding of Mathematics teaching in the initial years of Elementary Education in order to contribute to student learning.
\end{abstract}

Keywords: Mathematical Education; Action research; Early Years. 


\section{INTRODUÇÃO}

A Educação Matemática constitui-se em um dos desafios ao exercício profissional de professores/as nos anos iniciais, considerando a formação de professores, o ensino e a aprendizagem da Matemática. Partindo destes cenários nesta investigação foram realizadas leituras de referenciais teóricos que vem contribuindo para o ensino da Matemática: Fiorentini (1994); Smole, Diniz e Cândido (2007).

Por meio das leituras e reflexões destes autores foi possível perceber que o ensino da Matemática nos anos iniciais é de extrema importância, pois nesta etapa as crianças adentram no mundo das letras, números, domínio das quatro operações básicas, noções de espaço entre outros. Para isso, o professor pode proporcionar momentos de aprendizagem que envolvam metodologias de ensino com diferentes materiais concretos, jogos, dinâmicas, desafios.

Este estudo tem o objetivo de compreender o ensino da Matemática nos anos iniciais em uma Escola Municipal de Ensino Fundamental. Realizamos uma investigação com o intuito de perceber os modos de ensinar Matemática nos anos iniciais e como os alunos compreendem/aprendem a Matemática a partir das metodologias utilizadas.

Para melhor compreender estas ideias propomos a análise da Educação Matemática no contexto da prática com alunos dos anos iniciais. Este relato divide-se em cinco subtítulos principais nos quais apresentamos os aspectos introdutórios da pesquisa, o percurso metodológico, o contexto de análise, a descrição e análise de intervenção, e as considerações finais.

\section{METODOLOGIA}

Esta pesquisa em educação matemática, de natureza qualitativa que conforme Lüdke e André (1986, p. 11): “a pesquisa qualitativa supõe o contato direto e prolongado do pesquisador com o ambiente e a situação que está sendo investigada, via de regra através do trabalho de intensivo de campo". Nesta abordagem "preocupação com o processo é muito maior do que com o produto" (LÜDKE e ANDRÉ, 1986, p. 12); e as autoras ainda complementam que a complexidade do cotidiano escolar é sistematicamente retratada nas pesquisas qualitativas. 
A pesquisa-ação segundo Franco (2005) é a condição para um mergulho crítico na práxis de um grupo a ser estudado, do qual percebemos as expectativas, o oculto, que norteiam as práticas, as quais enfatizam o coletivo, que podem assumir o caráter crítico. Nesta pesquisa-ação buscou-se refletir sobre o ensino da Matemática, bem como, as metodologias de ensino utilizadas pelos professores, possibilitando o envolvimento e a participação dos sujeitos da pesquisa. Investigamos as metodologias exploradas nas aulas de Matemática do Ensino Fundamental e posteriormente foi planejada e desenvolvida uma intervenção pedagógica em uma turma previamente investigada.

Este relato foi realizado em uma escola da rede municipal (aqui nomeada de M1), em uma turma de segundo ano, nos anos iniciais do Ensino Fundamental. Primeiramente, foi conversado com a direção de uma escola estadual com o intuito de pesquisar e conhecer a realidade Matemática dos anos iniciais do Ensino Fundamental, mas percebemos a resistência em possibilitar um espaço para a pesquisa, o que acarretou em uma nova busca por uma instituição. Logo, encontramos uma escola que permitiu adentrarmos o ambiente escolar, fomos recebidas pela direção da escola, a qual mostrou-se interessada em ouvir as propostas para a coleta de dados e posterior intervenção.

Por meio do diálogo estabelecido com a direção, foi possível conhecer a organização, as rotinas, a estruturação do quadro de professores e um pouco do cotidiano escolar. Desta forma, percebemos a preocupação em ofertar momentos para o planejamento dos professores, tendo assim, aulas planejadas, pensadas com finalidades de ficar aquém das dificuldades encontradas em sala de aula, bem como em abranger os conteúdos de forma interdisciplinar.

Entre os instrumentos de coleta de dados, num primeiro momento foi utilizada a observação das aulas, em específico os momentos e períodos dedicados ao ensino da Matemática. A partir da interação dos pesquisadores com os sujeitos pesquisadoresativos foram observadas a participação no processo de ensino e as interações promovidas em suas aprendizagens, se há a possibilidade de expressar as dúvidas, opiniões, sugestões e se estas são aceitas pelos profissionais da educação.

Como instrumento de coleta de dados foram realizadas entrevistas com a finalidade de conhecer as realidades dos professores que atuam nos anos iniciais $\left(1^{\circ}, 2^{\circ}\right.$ e $3^{\circ}$ anos), suas perspectivas, angústias, formações e metodologias. Ressaltamos que 
neste escrito não apresentamos as análises da entrevista, mas este também serviu de base para refletirmos sobre o ensino da Matemática.

Posteriormente foram realizados os planejamentos das atividades de intervenção, através de conversas informais com a professora da turma, o estudo da realidade que ocorreu nas observações, e de leituras sugeridas pela professora através do plano de estudos da turma. Ainda como instrumento, tivemos a ação e execução das atividades planejadas. A partir da intervenção, enquanto pesquisadoras-ativas nos desafiamos a promover reflexões sobre as práticas que desenvolvemos.

A análise dos dados foi estruturada pela análise descritiva e interpretativa, considerando o tratamento qualitativo interpretativo desenvolvido nos estudos sobre a pesquisa-ação de Thiollent (1986). Para este autor na pesquisa-ação a análise de dados exige: "todo um trabalho de investigação e de interpretação dentro da problemática adotada e levando em conta a pesquisa com elementos "explicativos"” (THIOLLENT, 1986, p. 71). Considerando estes aspectos trata-se de uma análise que "poderá gerar reações e contribuir para a dinâmica da tomada de consciência e, eventualmente, sugerir o início de mais um ciclo de ação e de investigação" (THIOLLENT, 1986, p. 71).

Pela análise foi possível refletir sobre as metodologias e os planejamentos utilizados pelos professores, desta forma, realizamos os planejamentos e a intervenção com o intuito de compreendermos e refletirmos pela pesquisa-ação o ensino da Matemática nos anos iniciais.

\section{CONTEXTO DE ANÁliSE: REFLEXões A PARTIR DAS OBSERVAÇÕES}

Realizamos a observação da aula de Matemática, em uma turma do segundo ano, do primeiro ciclo nos anos iniciais do Ensino Fundamental. No dia da observação, o tempo estava abafado com pouco vento e todos os alunos estavam dentro da sala de aula, que é pequena e com pouca circulação de vento. A professora havia organizado a sala em fileiras de quatro alunos em cada, eles estavam bastante agitados, pois haviam voltado a pouco do intervalo.

Foi marcada a observação para uma quarta-feira, mas houve um imprevisto de modo que remarcamos para o dia seguinte. Em uma tarde de quinta-feira, ensolarada, nos foi oportunizado a observação das aulas de Matemática na turma do segundo ano 
composta por vinte alunos, sendo 9 meninas e 11 meninos. A professora havia planejado a confecção de um gráfico a partir das lendas do folclore, cada criança deveria votar qual mais gostavam e posteriormente registraram o gráfico no caderno. A professora utilizou o papel pardo para a confecção do cartaz, imagens das lendas e para marcar o voto das crianças um quadrado pequeno colorido. A atividade teve a duração de quarenta minutos.

Em uma conversa informal, a professora relatou: "Que pena que não vieram ontem, pois, havia planejado uma atividade legal, e as crianças estavam entusiasmadas para a realização". Percebemos que talvez a professora havia planejado algo "diferente" da rotina em função de nossa observação.

Após a confecção do gráfico, ela apenas contou quantos votos cada lenda teve, e não buscou a interpretação, que poderia ter sido realizada através de questionamentos como: “qual lenda teve empate?", “qual lenda teve menos votos?", "por que foi escolhida a lenda da Iara como ganhadora e não a do saci-pererê". Assim a atividade planejada foi atrativa para os alunos, uma vez que, era algo diferente da rotina, porém poderia ter sido mais explorada e problematizada pela professora, pois, poderia ter utilizado várias questões de interpretação, bem como, o registro em papel quadriculado ou no caderno de modo que estes venham a fixar a interpretação dos gráficos.

Neste contexto, relembramos os estudos das tendências de Fiorentini (1994), e percebemos nas observações que a professora contempla traços da tendência construtivista, pois trabalha com estruturas abstratas, priorizando o processo de construção e não os resultados, bem como, a tendência socioetnoculturalista, levando em consideração os conhecimentos prévios dos alunos e que a Matemática é um conhecimento prático e dinâmico. Desta forma, percebemos que a professora, após dezoito anos atuando nos anos iniciais adotou seus próprios métodos, buscando atender as necessidades que percebe das turmas. Porém, nas observações os alunos não manifestaram dúvidas ou questionamentos, pois a professora não dinamizou as atividades e utilizou apenas o quadro para explicação e anotação das atividades e o registro dos alunos se deu no caderno.

Ao observar a turma pensamos na proposta de intervenção, partindo de todo o contexto já analisado e exposto nos itens anteriores, foi possível desenvolver uma ação, para uma Educação Matemática que buscou contribuir com o trabalho já realizado pela 
professora. Foram desenvolvidas ações com ênfase na ludicidade, através de jogos que estimulassem o desenvolvimento da cooperação, trabalho em grupo, percepção, raciocínio, destreza, noção de espaço, coordenação motora, entre outros.

Planejamos as atividades, duas charadas retiradas do livro: Poemas Problemas de Renata Bueno (2012), o qual traz atividades de Matemática de maneira diversificada. Posteriormente, foi confeccionado o boliche com garrafas pet de $500 \mathrm{ml}$, em que cada garrafa continha um elemento diferente dentro (arroz, feijão, pipoca, e.v.a, farinha, lentilha), e rotuladas com um número de 1 a 12.

A intervenção ocorreu na escola M1, com o segundo ano do Ensino Fundamental, dia 14 de setembro de 2016, no turno da tarde, o dia estava ensolarado e quente, o que oportunizou o desenvolvimento das atividades em espaço mais amplo, no pátio da escola. Ao chegar na escola fomos recepcionadas pela diretora que nos encaminhou até a sala de aula da turma, as crianças estavam sentadas em fila, nos aguardando para realizar as atividades de Matemática. Neste dia, estávamos ansiosas, cheias de expectativas perante a realização das atividades, recepção dos alunos e professora, principalmente se os alunos iam gostar das atividades propostas, se teriam dificuldades, se iam participar ou não. Lembrando que a intervenção foi planejada de acordo com a realidade da turma, respeitando o nível de escolarização, possibilitando atividades lúdicas e significativas para a aprendizagem.

Ao adentrar à sala de aula fomos recepcionadas pelas crianças com "Boa tarde, sejam bem-vindas a nossa escola", perguntamos se lembravam quem éramos, responderam que "sim!". As atividades de intervenção tiveram a duração de uma hora e meia, a mais que o planejado.

\subsection{DESCRIÇÃO E ANÁLISE DAS ATIVIDADES DE}

\section{INTERVENÇÃO: DO PLANEJAMENTO A AÇÃO}

Após conversas informais com os alunos sobre quem éramos, explicamos como iria ocorrer a intervenção, solicitamos que formassem quatro grupos de cinco crianças cada, pois eram vinte crianças. Foi distribuído um número de um a cinco para cada criança, esse número era respectivo ao grupo. Assim que os grupos foram organizados iniciamos as atividades de resolução dos problemas: era grupo que faltava componentes, classes que não passavam nos espaços, evidenciando as dificuldades dos alunos em 
movimentar-se dentro da sala de aula e de organizar-se em dinâmicas que oportunizem estudos em grupos.

Depois dos grupos organizados, explicamos como iria ocorrer a intervenção, primeiramente na sala de aula as duas charadas Matemáticas, a primeira $(\mathrm{CH} 1)$ era a seguinte: "No aquário que comprei há dois peixes vermelhinhos, um laranja que é o rei, e mais nove amarelinhos. Ao todo, nadando juntos, quantos são os peixinhos?" A segunda $(\mathrm{CH} 2)$ era "O Teo tem um gato, que se chama Cissaninho. O menino colocou em seu prato 8 cenouras e 1 peixinho. Cissano comeu metade das cenouras, e o peixe inteirinho. Você sabe quanto sobrou em seu pratinho?"

As charadas envolviam a resolução de problemas matemáticos que exigiram dos alunos: a leitura, a interpretação, a lógica, adição, conjuntos, metade, inteiro, subtração. As charadas foram escritas no quadro branco uma por vez, e cada grupo fez o registro das resoluções em uma folha de ofício, posteriormente foi realizado a correção no grande grupo e verificado se os grupos acertaram ou não as charadas de forma individual.

O boliche foi realizado na área coberta da escola, encaminharam-se dois grupos por vez para jogar. Cada jogador teve a chance de arremessar a bola e pontuar para seu grupo. Após todos ter jogado, encaminharam-se para a sala de aula, e cada grupo fez a soma da pontuação, foi construída uma tabela para os alunos anotar os pontos do jogo de Boliche e realizar as adições. Durante o jogo do Boliche, percebemos um grande envolvimento pelos alunos, respeitando as regras do jogo, uma ordem a ser seguida para o bom desenvolvimento da atividade, os alunos não encararam como atividade de competição e sim estavam desfrutando/participando de um jogo que consideram legal que ligado a Matemática tornou-se agradável e de muitas aprendizagens. Após a realização das atividades (charadas e boliche) foi realizada a somatória dos pontos, para enfim declarar as ordens de classificações e identificar o grupo campeão.

$\mathrm{Na}$ organização dos grupos percebemos que os alunos demonstraram dificuldade em organizar-se no espaço da sala de aula, sendo esta pequena e com pouca ventilação, o que nos levou a refletir se realmente a P2 utilizava a metodologia de movimentação e trabalho em grupos dentro da sala de aula, ou ela apenas escreve no quadro e eles registram. 
Em conversas informais com a professora da turma, antes do planejamento da intervenção, esta relatou que a maioria das crianças não tinha dificuldade, eram apenas dois ou três alunos que tinham dificuldade. Nesta perspectiva para sala de aula, planejou-se as charadas $(\mathrm{CH} 1, \mathrm{CH} 2)$. A $\mathrm{CH} 1$ exigia que elaborassem uma conta de adição, a qual considerávamos fácil, porém, no decorrer da resolução surgiram muitas dúvidas e questionamentos, em que tivemos que parar e auxiliá-los na montagem da conta, explicando os conceitos de dezena e de unidade. A professora, acompanhou o andamento da intervenção e auxiliou nas explicações para os grupos. O que nos levou a refletir sobre como a importância de instigar os alunos na resolução de problemas que segundo Smole; Diniz; Cândido (2007, p.14),

Nossa proposta de utilização de jogos está baseada em uma perspectiva de resolução de problemas, o que, em nossa concepção, permite uma forma de organizar o ensino envolvendo mais que aspectos puramente metodológicos, pois inclui toda uma postura frente ao que é ensinar e, consequentemente, ao que significa aprender. Daí a escolha do termo, cujo significado corresponde a ampliar a conceituação de resolução de problemas como simples metodologia ou conjunto de orientações didáticas.

Nesta perspectiva, a professora poderia inserir metodologias que possibilitem reavaliar os conhecimentos dos alunos e sua didática, desta forma, conseguirá abranger mais as dificuldades encontradas pelos alunos, tornando os processos de ensino e de aprendizagem da Matemática, agradáveis. A CH2, abrangeu a composição de conjuntos e exigia que a montagem de duas contas, interpretação e raciocínio lógico, o que foi de difícil resolução dos alunos, pois, não compreendiam que a questão envolvia dois objetos diferentes e duas contas separadas, e novamente não conseguiram armar a conta para resolvê-la. Os que conseguiram resolver pelo raciocínio lógico sabiam o resultado, mas não conseguiam registrar na folha. Assim, o restante da turma solicitou auxílio, o que exigiu bastante tempo para as explicações.

Percebemos que os alunos ao serem submetidos a experiências/desafios novos, demonstraram dificuldade em relacionar a nova maneira dos problemas $(\mathrm{CH} 1, \mathrm{CH} 2)$, com os conteúdos que estudam diariamente. Desta forma, a Matemática pode ser ensinada de modo que instigue os alunos a resolução de diferentes problemas, e apresentá-los de formas diversificadas.

Após a realização das charadas, dois grupos foram encaminhados para o pátio da escola para a realização do Boliche, e os outros ficaram na sala terminando as atividades. Com o jogo do boliche, notamos como os alunos gostam de realizar 
atividades diferenciadas em outros espaços da escola. A maioria expressava o desejo de que "gostariam de jogar novamente", demostrando euforia e entusiasmo com o jogo. Com a finalização do jogo, notamos que os alunos gostaram, principalmente por estarmos em outro ambiente que não fosse a sala de aula, e que é possível tornar a Matemática prazerosa através de atividades diferenciadas.

Ao nos despedir, os alunos foram calorosos, agradeceram, alguns chegaram a nos abraçar. A professora da turma também agradeceu e nos relatou que a intervenção contribui para perceber as dificuldades dos alunos perante a Matemática. Percebemos o quanto foi importante proporcionar atividades lúdicas como jogos para o ensino da Matemática, principalmente atividades como o jogo de boliche que tem caráter interdisciplinar, estimulando o desenvolvimento dos alunos em vários aspectos, possibilitando o movimento e a corporeidade na Educação Matemática também. Segundo Borin (1996, p.9), o jogo nas aulas de Matemática possibilita,

(...) diminuir bloqueios apresentados por muitos de nossos alunos que temem a Matemática e sentem-se incapacitados para aprendê-la. Dentro da situação de jogo, onde é impossível uma atitude passiva e a motivação é grande, notamos que, ao mesmo tempo em que estes alunos falam Matemática, apresentam também um melhor desempenho e atitudes mais positivas frente a seus processos de aprendizagem.

Corroborando com as ideias de Borin (1996), sabemos que muitos alunos apresentam dificuldades na aprendizagem de conteúdos da Matemática, mas cabe aos professores planejar aulas com métodos de ensino que possibilitem aos alunos diferentes formas de resolução dos problemas, o que os instiga a aprender e não ser "temedores" da Matemática.

Após a realização das atividades, em conversa informal com a professora, esta relatou como foi importante a intervenção, pois, possibilitou perceber as dificuldades apresentadas pelos alunos, que no cotidiano escolar, durante as suas aulas não foi possível notar, ou seja, pela pesquisa-ação, foi possível que a professora também refletisse sobre a sua prática nas aulas de Matemática. No momento em que nos possibilitou espaço para desenvolver a intervenção, também passou a ser pesquisadora, pois acreditou na nossa intervenção e através desta pesquisa-ação passou a perceber a turma com um olhar mais reflexivo, e até mesmo crítico sobre o ensino e as aprendizagens dos alunos. O que nos levou a refletir a partir do observado que a professora, possivelmente realiza em suas aulas de Matemática contas prontas, já 
armadas, em que os alunos precisam apenas resolver, o que não possibilita aos alunos pensar como fazer (interpretação) e armar estas contas (raciocínio lógico), limitando o ensino da Matemática.

Desta forma, o ensino da Matemática pode priorizar a elaboração e o planejamento de atividades que possibilitem a argumentação, o pensar crítico sobre o aprendizado promovendo a resolução de problemas. Nesta perspectiva, o ensino da Matemática pode envolver os alunos com diferentes metodologias e problemas a serem resolvidos, para que desta forma, tornem-se alunos pensantes, críticos, criativos, autônomos, questionadores e que dialogam as suas dúvidas acarretando em uma aprendizagem significativa.

\section{CONSIDERAÇÕES FINAIS}

Através da intervenção, com atividades lúdicas, foi possível perceber, que as crianças possuem dificuldades em aprender Matemática, mesmo em elementos básicos como armar o cálculo, no decorrer da intervenção foi necessário explicar e relembrar como se realizava a estrutura operatória do cálculo (na $\mathrm{CH} 1$ ) e diferenças entre conjuntos (na $\mathrm{CH} 2$ ), por vezes, essas dificuldades passam despercebidas pelo professor, pois, este prende sua atenção em escrever tudo no quadro e os alunos registram no caderno, tornando assim, o ensino um pouco mecânico, de modo que impossibilita as crianças elaborar um processo de raciocínio para a resolução dos problemas/atividades. Neste contexto, foi possível perceber através da pesquisa-ação que a professora utilizava metodologias tradicionais, investindo pouco no lúdico e não proporcionando ambientes e atividades diferenciadas.

Percebemos que o ensino da Matemática pode ser melhorado através de inovações das metodologias, como a troca do ambiente que pode contribuir ao possibilitar as crianças um estímulo diferenciado, um novo método/jeito de "ver" a Matemática, indo além dos limites da sala de aula, possibilitando uma Educação Matemática. Neste caso, vale ser relembrado o jogo de boliche realizado na intervenção, na área externa e coberta da escola, sendo esta uma atividade com materiais reciclados em ambiente diferenciado, que envolveu o lúdico para tornar a aprendizagem significativa. Enquanto professoras e pesquisadoras surgiram inquietações, questionamentos, e esta investigação desencadeou reflexões sobre as metodologias utilizadas para o ensino da Matemática nos anos iniciais do Ensino Fundamental. 
Tendo em vista os aspectos observados, e as curiosidades iniciais sobre a Matemática que foram investigadas, as observações e a intervenção, percebemos que o ensino da Matemática pode estar deixando algumas lacunas nos anos iniciais, o que é um dos fatores que acarretam em futuros "temedores" da Matemática nos anos finais do Ensino Fundamental e no Ensino Médio. A pesquisa-ação possibilitou uma visão da realidade de sala de aula da atualidade, o que em alguns aspectos nos deixou frustradas com as metodologias de ensino da Matemática utilizadas, sendo estas tradicionais, o oposto do que nos é instigado na formação inicial, o que nos levou a refletir pontos fundamentais para este processo, como a utilização do lúdico, os materiais e os ambientes diferenciados.

Em virtude da análise apresentada e os aspectos pesquisados, foi possível ressignificar conceitos sobre o ensino e as metodologias da Matemática, bem como, o ser professor em sala de aula, o que exige a reflexão das ações e das práticas, e a percepção das dificuldades dos alunos. Deste modo, para que o planejamento esteja de acordo com a realidade e a aprendizagem seja significativa, levamos em consideração os conhecimentos prévios e a faixa etária dos alunos. Acreditamos que a investigação oportunizou reflexões no contexto da prática docente e permitiu ressignificar a educação Matemática e seu ensino nos anos iniciais do Ensino Fundamental. Portanto, este relato possibilitou como professoras pesquisadoras de nossas próprias práticas em movimento de pesquisa-ação ampliar nossas compreensões sobre o ensino da Matemática nos anos iniciais do Ensino Fundamental de modo a contribuir para a aprendizagem dos alunos.

\section{REFERÊNCIAS}

BORIN, J. Jogos e Resolução de Problemas: uma estratégia para as aulas de Matemática. São Paulo: IMEUSP, 1996.

BUENO, R. Poemas Problemas. São Paulo: Editora do Brasil, 2012.

FIORENTINI, D. Rumos da Pesquisa Brasileira em Educação Matemática: o caso da produção científica em cursos de pós-graduação. 1994. 414 f. Tese (Doutorado em Educação) - Faculdade de Educação, Universidade Estadual de Campinas. Campinas, 1994.

FRANCO, M. Pedagogia da pesquisa-ação. Educação e Pesquisa. São Paulo, v. 31, n. 3, p. 483-502, set./dez. 2005.

LÜDKE, M.; ANDRÉ, M. E. D. A. Pesquisa em Educação: abordagens qualitativas. São Paulo: EPU, 1986. 
SMOLE, K. S; DINIZ, M. I; CÂNDIDO, P. Jogos de Matemática de $\mathbf{1}^{\circ}$ a $5^{\circ}$ Ano. Porto Alegre: Artmed, 2007.

THIOLLENT, M. Metodologia da pesquisa-ação. São Paulo: Cortez, 1986. 